\title{
Prediction of Hypothyroidism after Hemithyroidectomy: A Biochemical and Pathological Analysis.
}

\author{
${ }^{1}$ Dr. Abhinav Rathi, ${ }^{2}$ Dr. Dhara Sharma, ${ }^{3}$ Dr. Beni Prasad \\ ${ }^{1}$ Assistant Professor Department. Of ENT \& Head \& Neck Surgery JNU IMSRC, Jaipur \\ ${ }^{2}$ M.S. ENT Senior Resident Department. Of ENT \& Head \& Neck Surgeryjnu IMSRC, Jaipur \\ ${ }^{3}$ M.S. ENT Professor \& Head Department. Of ENT \& Head \& Neck Surgery NIMS, Jaipur
}

\begin{abstract}
The possibility of postsurgical hypothyroidism after hemithyroidectomy is an underappreciated complication. We intended to evaluate the incidence of development of hypothyroidism after hemithyroidectomy and to analyze the relationship of posthemithyroidectomy hypothyroidism with preoperative biochemical parameters(preoperative TSH,Thyroid antibody levels) and postoperative histopathological findings. From November 2010 to May 2011, 60 cases of hemithyroidectomized patients were analyzed. Postoperative hypothyroidism developed in 19 patients(31.66\%). Preoperative TSH value was significantly higher in the hypothyroid group $(2.68 \mu \mathrm{IU} / \mathrm{ml})$ compared to the euthyroid group $(1.39 \mu \mathrm{IU} / \mathrm{ml})$. Elevated thyroid antibody(TAA) levels were observed in 53\% of patients developing postoperative hypothyroidism as compared to $12 \%$ of patients who remain euthyroid $(p=0.00077)$. Moreover, patients with a higher grade of lymphocytic infiltration were found to have a higher probability of developing hypothyroidism. In addition, our findings support the recommendation for regular serum TSH follow-up at least for 6 months after hemithyroidectomy.

Keywords : Hemithyroidectomy, Hypothyroidism, thyroid autoantibodies , microsomal antibody, thyroglobulin antibody
\end{abstract}

\section{Introduction}

The development of hypothyroidism following hemithyroidectomy for benign nontoxic thyroid disease is an underappreciated complication. In the past, physicians used to place most hemithyroidectomy patients on prophylactic thyroid suppression therapy . A consequence of this practice was increasing number of patients developing subclinical thyrotoxicosis leading to various endocrine and cardiac complications.So this study is designed to identify those patients who are at increased risk of developing hypothyroidism after hemithyroidectomy and the biochemical and pathological factors which can help us to identify these high risk patients. Several studies have demonstrated an incidence of post-hemithyroidectomy hypothyroidism ranging from $5.0 \%$ to $41.9 \%$. According to a study conducted by Kristen A. Seiberling et al $24.1 \%$ of the patients who had undergone hemithyroidectomy had become hypothyroid after surgery. Similarly a study reported in 2000 by McHenry and Slusarczyk found that the incidence of postoperative hypothyroidism was $35 \%{ }^{2}$

\section{Aims And Objectives}

1) To assess the incidence of hypothyroidism after hemithyroidectomy for benign thyroid disease.

2) To identify risk factors for the development of hypothyroidism.

3) To assess the time interval for development of hypothyroidism following hemithyroidectomy.

\section{Materials And Methods}

This study was conducted on the patients who had undergone hemithyroidectomy (unilateral thyroid lobectomy and isthmusectomy) in the department of Otorhinolaryngology, head \& neck surgery, SMS Medical College \& Hospital from November 2010 to May 2011.

Total number of cases were 60 in number.

\section{Criteria for selection of cases}

a) All patients with benign thyroid swellings.

b) Patients should be euthyroid.

\section{Criteria for exclusion of cases}

a) Hypothyroid and hyperthyroid patients

b) Patients who have undergone previous thyroid surgery.

c) Patients with preoperative diagnosis of malignancy.

d) Age less than 18 years or more than 90 years. 
e) Previous use of any medication known to alter thyroid hormone or serum TSH level.

\section{Pre Operative Assessment}

All patients underwent the following investigations preoperatively .

a) Thyroid Function Tests: serum $\mathrm{FT}_{3}, \mathrm{FT}_{4}$ and $\mathrm{TSH}$ estimation.

b) FNAC(Fine needle aspiration cytology)

c) USG(Ultrasonography)

d) Thyroid autoantibodies: Serum Thyroglobulin Antibody(TGA) and Serum Anti - TPO

\section{Postperative Evaluation}

(a) Weight of the resected gland in grams.

(b) Histopathology.

\section{Followup}

Followup examination was done at 1 month, 3 months \& 6 months. At each visit their thyroid profile was done to see for development of hypothyroidism.

\section{Observations/Results}

Table 1 Thyroid antibody and postoperative thyroid status

\begin{tabular}{|l|c|c|}
\hline & Postoperative Euthyroid $(\mathrm{n}=41)$ & Postoperative Hypothyroid $(\mathrm{n}=19)$ \\
\hline Anti TPO Ab Positive & $2(4.8 \%)$ & $6(31.5 \%)$ \\
\hline TGA Positive & $2(4.8 \%)$ & $3(15.7 \%)$ \\
\hline Both Positive & $1(2.4 \%)$ & $1(5.2 \%)$ \\
\hline No Ab & $36(87.8 \%)$ & $9(47 \%)$ \\
\hline Total & $41(100 \%)$ & $19(100 \%)$ \\
\hline
\end{tabular}

$\mathrm{p}=0.00077$

Table 2 Age, Sex, Family history of thyroid disease, side of operation \& weight of resected tissue.

\begin{tabular}{|c|c|c|c|c|}
\hline S.No. & & $\begin{array}{l}\text { Postoperative euthyroid } \\
\text { patients }(n=41)\end{array}$ & $\begin{array}{l}\text { Postoperative } \\
\text { hypothyroid } \\
\text { patients }(n=19)\end{array}$ & $\mathrm{p}$ value \\
\hline 1. & Age: Mean (Range) & 36.36 years $(20-52)$ & $\begin{array}{l}39.42 \text { years }(22- \\
60)\end{array}$ & 0.064 \\
\hline 2. & $\begin{array}{l}\text { Sex } \\
\text { Female } \\
\text { Male }\end{array}$ & $\begin{array}{l}38(92.6 \%) \\
3(7.3 \%)\end{array}$ & $\begin{array}{l}18(94.7 \%) \\
1(5.2 \%)\end{array}$ & 0.7667 \\
\hline 3. & $\begin{array}{l}\text { Family history of thyroid disease } \\
\text { yes } \\
\text { no } \\
\text { unknown }\end{array}$ & $\begin{array}{l}5(12.1 \%) \\
34(82.9 \%) \\
2(4.8 \%) \\
\end{array}$ & $\begin{array}{l}2(10.5 \%) \\
16(84.2 \%) \\
1(5.2 \%) \\
\end{array}$ & 0.8514 \\
\hline 4. & $\begin{array}{l}\text { Side of operation } \\
\text { right } \\
\text { left }\end{array}$ & $\begin{array}{l}24(58.5 \%) \\
17(41.4 \%)\end{array}$ & $\begin{array}{l}12(63.15 \%) \\
7(36.84 \%)\end{array}$ & 0.7339 \\
\hline 5. & $\begin{array}{l}\text { Weight of resected tissue : Mean } \\
\text { (Range) }\end{array}$ & $19.31 \mathrm{gm}(14-38)$ & $20.42(13-39)$ & 0.8255 \\
\hline
\end{tabular}

In our study ,60 patients underwent Hemithyroidectomy during the 7 months period from November 2010 to ay 2011. 19 patients(31.66\%) developed biochemical hypothyroidism in the postoperative period. Out of 19 patients ,7 patients developed hypothyroidism at 1 st month, 10 patients at $3^{\text {rd }}$ month and 2 patients at 6 months . Out of 27 patients with higher preoperative TSH values, 15 (55.55\%) developed hypothyroidism postoperatively. On the other hand, $4(12 \%)$ out of 33 patients with lower normal TSH values developed hypothyroidism postoperatively. This difference is statically significant $(\mathrm{p}=0.00032)$. As shown in table 1 , thyroid antibodies were positive in 15 patients. Out of these 15 patients, 10 patients $(66.66 \%)$ developed postoperative hypothyroidism. 3 Patients $(7 \%)$ in the Euthyroid group and 9 patients $(47.3 \%)$ in the hypothyroid group had chronic lymphocytic thyroiditis and hashimoto's thyroiditis as the primary diagnosis on histologic examination of the resected specimen.

\section{Discussion}

In our study , 19 patients(31.66\%) developed biochemical hypothyroidism in the postoperative period .Mean time to diagnose hypothyroidism in our study is $2.58 \pm 1.54$ months . Similarly in study by Kirsten A Seiberling et al (2007) most of the patients developed hypothyroidism within 6 months with majority becoming hypothyroid at the end of 2 months. 
In our study patients with TSH in the upper end of the normal laboratory range (2.5-4.0 mIU/L) are significantly more likely to develop postoperative hypothyroidism $(55.55 \% \mathrm{v} / \mathrm{s} 12.12 \%)$ than patients with TSH in the lower end (0-2.4 mIU/L). Higher normal Preoperative TSH may be associated with decreased functional reserve of the thyroid gland.As hemithyroidectomy reduces the mass of functional thyroid tissue, patients with higher normal TSH , are likely to deteriorate As shown in Table 1, 52.63\% of patients in hypothyroid group had raised TAAs levels preoperatively compared to $12 \%$ patients in euthyroid group. Chou et al (1999) concluded that increased TMA levels were the only independent factor causing postoperative hypothyroidism. In our study positive lymphocytic infiltration was significantly higher in the hypothyroid group than in the euthyroid group (47\% v/s $7 \%$ ). Berglund et al determined that $33 \%$ of patients with pronounced lymphocytic infiltration in the thyroid gland developed postoperative hypothyroidism compared with only $4 \%$ of patients with minimal infiltration. ${ }^{4}$ As shown in table 2 , there are no significant differences with respect to age $(p=0.064)$, sex $(p=0.7667)$, family history of thyroid diseases $(\mathrm{p}=0.8514)$, the side of surgery $(\mathrm{p}=0.733)$ and the weight of resected tissue $(\mathrm{p}=$ 0.8255 ) between the euthyroid and hypothyroid groups.

\section{Conclusion}

The incidence of hypothyroidism following hemithyroidectomy in our study is $31.66 \%$ and is comparable to other published series Subjecting all patients undergoing hemithyroidectomy to repeated thyroid function tests within the first year would appear to be excessive given that such testing will be unnecessary in over $60 \%$ of them. Moreover past practice of administering low dose thyroxine to patients who had undergone hemithyroidectomy has been abandoned due to increased awareness of the morbidity associated with levothyroxine.Therefore, the identification of risk factors for prediction of the development of early hypothyroidism would be clearly beneficial. A number of conclusions were drawn from our study regarding the risk factors.A high normal preoperative TSH (2.5-4.0 mIU/L), elevated thyroid antibody levels( antiTPO and TGA ) and the presence of thyroiditis on istology predispose patients to development of hypothyroidism post hemithyroidectomy and are indicators for close monitoring. Age, gender, family history of thyroid disease, side of thyroid surgery and weight of resected tissue were not significant risk factors for hypothyroidism.

$\begin{array}{lll} & & \\ \text { TSH } & : & \text { Thyroid Stimulating Hormone. } \\ \text { FNAC } & : & \text { Fine Needle Aspiration Cytology. } \\ \text { fT }_{3} & : & \text { Free } \mathrm{T}_{3} \\ \mathrm{fT}_{4} & : & \text { Free } \mathrm{T}_{4} \\ \text { Anti TPO } & : & \text { Anti thyroid peroxidise. } \\ \text { TGA } & : & \text { Thyroglobulin antibody. } \\ \text { Ab } & : & \text { Antibody. } \\ \text { TAA } & : & \text { Thyroid Autoantibodies. } \\ \text { TMA } & : & \text { Thyroid microsomal antigen. }\end{array}$

\section{References}

[1]. Ear,Nose and amp ; Throat Journal ,May,2007 by Kristin A.Seiberling,Jose C .Dutra,Sanija Bajaramovic.

[2]. McHenry CR, Susarczyk SJ . Hypothyroidism following hemithyroidectomy : Incidence , risk factors , and management .Surgery $2000 ; 128: 994-8$

[3]. Chou F-F, Wang P-W ,Huang S-C . Results of subtotal thyroidectomy for Graves' disease .Thyroid1999; $9: 253-7$.

[4]. Berglund J, Bondeson L, Christensen SB ,Tibblin S .The influence of different degrees of chronic lymphocytic thyroiditis on thyroid function after surgery for benign, non-toxic goitre.Eur J Surg $1991 ; 157: 257-60$. 